\title{
La vivienda de patios como patrimonio urbano constitutivo de la identidad regional latinoamericana'.
}

\author{
Courtyard housing as latin american regional identity \\ urban heritage.
}

Cómo citar:

Carmignani, M (2018). La vivienda de patios como patrimonio urbano constitutivo de la identidad regional latinoamericana. Designia 6(1), 79-97.

${ }^{1}$ Este artículo de reflexión se deriva de investigaciones realizadas en el marco de la Cátedra de Historia de la Arquitectura y el Urbanismo latinoamericanos de la Facultad de Arquitectura, Urbanismo y Diseño de la Universidad Nacional de Córdoba (Argentina).

*Arquitecta FAUDI, UNC, 2007. Córdoba, Argentina. Magister "Conservación y Rehabilitación del Patrimonio Arquitectónico", FAUDI, UNC 2016. Docente Investigador Categoría 5, FAUDI y Profesor asistente Cátedra de "Historia de la Arquitectura y el Urbanismo Latinoamericanos III A,

UNC. Prof. Asistente, Cátedras de "Historia del Arte B" y "Arquitectura y Urbanismo", Facultad de Derecho. UNLZ. maritacarmignani@gmail.com ORCID: 0000-0002-9658-9926
Palabras clave:

Diseño, identidad, casa unifamiliar, región.

Key words:

Design, identity, single family hose, region.

Recibido: $21 / 10 / 2017$

Aceptado: 08/08/2018

\section{Resumen:}

El presente artículo expone reflexiones acerca del estudio de la vivienda en Latinoamérica y de cómo desde el enfoque académico se propone su apreciación crítica para una posterior transferencia del conocimiento en el proceso de diseño propio de cada alumno. Se aborda así el análisis de la tipología residencial, entendida como un hecho antropológico, mediante la identificación y selección de manifestaciones de la vivienda hispanoamericana de patios existentes en Argentina y a lo largo del continente, las cuales corroboran desde el diseño una correlación directa de identidades regionales que se encuentran en constante construcción. 


\begin{abstract}
:
This article reflects on both the study of housing in Latin American and how to critically assess it from an academic approach in order to incorporate the knowledge into each student's design process. The residential typology, considered as an anthropological reality, is thus analyzed by identifying and selecting manifestations of Hispanic-derived courtyard housing in Argentina and all over the continent, which corroborates from the design a direct correlation of evolving regional identities.
\end{abstract}

\title{
LA IMPORTANCIA DEL ESTUDIO DE LA TIPOLOGÍA RESIDENCIAL EN EL DISEÑO ARQUITECTÓNICO
}

La labor realizada desde el año 2006 en el marco de la cátedra "Historia de la Arquitectura y el Urbanismo latinoamericanos", correspondiente al Nivel IV en la Facultad de Arquitectura de la Universidad Nacional de Córdoba, deja en evidencia elementos cuya profundización es necesaria al momento de analizar, pensar y diseñar la vivienda individual latinoamericana, arquitectura esencial y referente de identidad por excelencia que se convierte en el principal motivador de este trabajo investigativo. Desde nuestra unidad académica, verificamos en las materias de diseño una escasez de ejercicios proyectuales enfocados específicamente en dicha vivienda, como también una falta de base conceptual de los alumnos para la construcción de sus propias ideas. Esto sucede en medio de una "modernidad líquida", como la denomina Bauman (2002), signada por crisis y revisión de paradigmas establecidos, fragmentación, relativismo, caos, dispersión, pluralidad, ambigüedad, ingravidez, complejidad y culto a la imagen por sobre todo. Asimismo, hemos encontrado escasa información bibliográfica publicada acerca de la producción arquitectónica residencial en Latinoamérica en distintos períodos históricos, al tiempo que actualmente presenciamos la constante destrucción del patrimonio representado en unidades habitacionales, irrecuperable testigo de nuestro devenir. Por consiguiente, la cátedra ha definido como objetivos generales: 
- Cerrar el ciclo de las historias, como última materia curricular, al interrelacionar el bagaje de conocimientos adquiridos con el particular desarrollo latinoamericano.

- Promover una reflexión crítica sobre la arquitectura y la ciudad latinoamericanas. - Transferir tal actitud al proceso de proyectación del alumno en aras de ampliar su panorama cultural y brindarle elementos para el autoanálisis y la autocrítica.

El programa desarrolla contenidos históricos relacionados con la Arquitectura y el Urbanismo en Córdoba, Argentina y Latinoamérica, según diversas unidades temáticas que comprenden: Modernidad y Postmodernidad en el siglo XX; período Republicano del siglo XIX; Colonia entre los siglos XV y XIX en Hispanoamérica y Brasil; y época Prehispánica o de las culturas aborígenes mesoamericanas y sudamericanas. Como herramientas de análisis de las obras y los autores se aplican conceptos instrumentales, entre los cuales se cuentan: regionalismos y región; identidad y patrimonio; modalidades de transculturación; mestizajes; procesos históricos compartidos; tradición y vanguardia; universal y particular; internacional y regional; central y periférico. A su vez, la hipótesis base para las exploraciones es: "la región puede ser entendida como soporte de la identidad".

Adicionalmente, se realiza una caracterización exhaustiva del patrimonio doméstico, enfocada en la reflexión acerca de cómo la vivienda hispanoamericana de patios, enmarcada en determinados tiempos y espacios, puede colaborar de manera trascendente y dialéctica en la construcción permanente y dinámica de la identidad regional y latinoamericana, como también manifestar y reflejar diversos procesos de hibridación que le confieren singularidad. La intención es que el alumno articule los contenidos y los transfiera a su propio proceso de diseño.

En este contexto, para el presente trabajo se adoptó una metodología de tipo cualitativo-exploratorio con el fin de identificar las características representativas del habitar en la vivienda argentina de las grandes ciudades. Asimismo, se observó y analizó el uso de esta tipología y su relación con la ciudad al conformar un binomio en el cual se evidencia su rol protagónico en la densificación de la trama y el tejido urbano. Por otra parte, se llevó a cabo el estudio de casos, es decir, el mapeo general, documental y gráfico de ejemplos puntuales en el continente, siempre vinculados a los entornos donde se originan, con el propósito de extraer conclusiones y modos de hacer y pensar comunes, sin abordar un examen convencional y pormenorizado de tipos arquitectónicos. Se entiende que el enfoque fenomenológico prevaleciente en la investigación no parte del diseño de una teoría sino de una percepción del mundo conocido, desde la cual es posible interpretar y vincular diferentes componentes de la realidad desde una visión compleja. 
El recorrido aquí presentado se circunscribe, de manera general, a Hispanoamérica -todos aquellos territorios que fueron colonias españolas- y de manera particular a los ámbitos urbanos establecidos desde el arribo de España a tierras americanas hasta nuestros días. Se considera que desde el encuentro de los dos mundos comenzaron a producirse procesos de transculturación y, con ellos, la hibridación y el mestizaje manifestados en las tipologías arquitectónicas analizadas.

Por lo tanto, se han seleccionado obras que evidencian esa hibridación y permiten ejemplificar la articulación entre teoría y diseño. En relación con esto último, cabe destacar que el patio, con su esencia espacial y simbólica, es un elemento común a lo largo del continente y de carácter principal en las composiciones tipológicas, si bien cada una de estas define una relación intrínseca y singular con su región.

Para todos los casos elegidos, las variables de análisis sistematizan el proceso de transferencia mediante el estudio del contexto espacio-temporal y sociocultural donde se origina la obra. Se tienen en cuenta: localización, autor y año de la construcción; tipología y tecnología; espacio, lenguaje y usos.

El objetivo general apunta al desarrollo del tipo funcional como herramienta de análisis que aporte a la valoración del patrimonio arquitectónico residencial en un marco de reconocimiento de la identidad latinoamericana que incluya y resignifique particularidades regionales. Los objetivos específicos comprenden: sistematizar una base de datos, consistente en un registro documental, gráfico y analítico de viviendas de patio; elaborar un marco teórico metodológico aplicable a casos de la región; y aportar a la divulgación de la producción arquitectónica residencial del continente a través del estudio de la tipología en distintos momentos históricos.

\section{LA IDENTIDAD EN LATINOAMÉRICA}

Es posible definir la identidad como la resultante de un particular modo de pensamiento y acción que diferencia a los hombres entre sí y se construye a través de su historia. Puede considerarse un valor emergente, con entidad propia en un universo limitado, en el cual determinadas variables se amalgaman armónicamente para producir una síntesis entre teoría y praxis. Dicho concepto está enmarcado en un tiempo y un espacio que configuran un particular ambiente humano en función de un sistema de valores y según su horizonte cultural. Al ser una construcción comunitaria, cotidiana y continua, la identidad existe cuando es conscientemente asumida y reconocida por otros. De hecho, funda un sentido de pertenencia a un conjunto y circunscribe la suma de situaciones de acuerdo con las cuales los miembros de un colectivo pueden decir "nosotros" en un sentido enfático. 
Respecto a la identidad latinoamericana, para el pensador chileno Miguel Rojas Mix (2004), es "un proyecto a futuro". En una dirección afín, Larraín (1998) reconoce su permanente construcción y reconstrucción desde dos concepciones alternativas y complementarias. Por una parte, se le aborda dentro de nuevos contextos mediante un acercamiento histórico, aún no resuelto y concebido definitivamente como un conjunto fijo de cualidades, valores y experiencias comunes. Esta mirada se centra por igual en el pasado y el futuro para dejar atrás las preguntas sobre qué somos y reflexionar acerca de aquello que queremos ser. Por otra parte, existe la concepción esencialista de una identidad cultural a la cual se define como un hecho acabado, un consolidado establecido de costumbres comunes y valores fundamentales compartidos, cuya conformación se dio en el pasado y ha quedado fija de una vez y para siempre. Sobre este particular, ciertamente cada pueblo o nación tiene su esencia, una experiencia propia, proveedora de un compendio estable de códigos, significados y marcos de referencia trascendentes a las diferencias superficiales y a los cambios históricos. Aunque tal esencia puede, temporalmente, extraviarse, abandonarse, ignorarse o enmudecerse, no puede desaparecer por completo.

\section{LA VIVIENDA COMO ESPACIO DE PERTENENCIA, IDENTIDAD Y APRO- PIACIÓN}

\section{Y la casa misma tendrá su historia, será envoltorio, contendrá olores, texturas y colores además de calor humano. Será única, será rincón y será nido, será refugio, espacio sagrado, lugar en donde se reúne la familia y será al mismo tiempo el lugar de la soledad y del terror. Geraldine Novelo}

La casa es el primer lugar de identificación del ser humano. Por ello, creemos necesario examinar el nexo entre vivienda e identidad individual y colectiva. 
La casa, según Josep Montaner (2011), es como un microcosmo en el universo. Ella crea un mundo, a veces abierto hacia el paisaje, donde el hombre acumula cosas, tales como obras de arte, artesanías, plantas, árboles, libros. En Latinoamérica, quizá esto sea un resabio de las prácticas del antiguo colonizador, del viajero descubridor e, incluso, puede evocar la nostalgia y la necesidad del náufrago.

Desde sus orígenes, la vivienda asumió un rol esencial en la cultura occidental. Para Taberna (2008), no solo es el escenario donde ocurren los acontecimientos trascendentes de la vida, sino que también en torno al hogar, el grupo doméstico da forma al proyecto de su existencia. Por lo tanto, sobrepasa la condición de cobijo donde se sobrevive a las inclemencias del medio ambiente para convertirse en el espacio posibilitador del desarrollo de un sentido del propio yo. Los muros delimitadores de entorno íntimo pasan a ser una huella de la vida de cada persona, una expresión de su voluntad de permanecer. El hombre puede ser definido, en este contexto, como "el que habita" y la casa como el principal espacio donde integra pensamientos, recuerdos y sueños.

Desde una dimensión simbólica, la vivienda según Yujnovsky (1984), representa una conjunción de servicios que responde a necesidades humanas primordiales, entre ellas albergue, refugio y protección, como parte de un grupo social, un ambiente y un espacio. Alcalá (1995) sostiene además que a partir del hecho antropológico, dinámico e histórico, la vivienda reúne lo espacial, económico, social, político, institucional y cultural. A su vez, según afirma Iglesia (2006), es el sitio donde la persona experimenta un adentro y un afuera, una conciencia del interior y el exterior, completada con la presencia grupal familiar y la cotidianidad.

Cabe destacar lo señalado por Romero (1997) en el sentido de que el conocimiento de los cambios de la vivienda y sus expresiones territoriales puede aportar claves para ulteriores análisis en las dimensiones sociales y culturales, pues el espacio doméstico es un registro privilegiado de las acciones y los comportamientos de los individuos. 


\section{LA VIVIENDA DE PATIOS EN LATINOAMÉRICA: APORTES AL DISEÑO}

La presencia de vivienda de patios puede verificarse desde las aldeas neolíticas hasta las construcciones helenísticas de ciudades regulares como Priene, Mileto, Timgad o Pompeya. Con la intensa romanización derivada de la expansión del Imperio romano, la domus llega a la península ibérica, donde la tipología a base de patios se asienta en el sur de España y se funde luego con rasgos de la cultura musulmana: ingreso protegido, introversión, directrices quebradas y privacidad.

\section{Vivienda colonial}

Durante el período colonial de la actual Latinoamérica, la casa formó parte del desarrollo y del crecimiento urbano de los territorios bajo dominio español y portugués. En la vivienda andaluza, con sus habitaciones reunidas alrededor del patio -ámbito social, familiar y laboral- se encuentra el principal antecedente de la establecida en América. Dicho modelo es transculturado, si bien se incorporan variaciones según el tipo y trazado de las ciudades para resolver así con elementos distintivos las peculiaridades de cada sitio dentro de una estructura básica común.

Según explica Silva (2001), la forma, el tamaño y la ubicación de los patios en la casa, junto a la introversión funcional y elementos como galerías, zaguanes y fachadas barrocas, se suman a los recursos y las técnicas constructivas que deben responder a los climas regionales. Estos condicionantes, en su conjunto, generan propuestas singulares para cada lugar. Aun así, es posible destacar rasgos comunes entre estas viviendas a lo largo del territorio hispanoamericano:

- Localización: entidades casi autónomas, de sólida presencia exterior, situadas cerca de la plaza de armas para configurar la manzana, el tejido y la imagen urbana.

- Tipología: organización en torno a patios de distinto carácter y función. El ingreso se da por un zaguán ornamentado que actúa como tamiz visual entre el interior y el exterior y da acceso al patio principal de recibo, el cual concentra la dinámica familiar e incorpora la vegetación y la escalera, si se cuenta con dos niveles. Las salas más importantes y de servicio se disponen alrededor de patios de similares jerarquías. 
Esta distribución representa la introvertida vida doméstica de estructura patriarcal y disgrega las funciones asociadas al comercio, la familia y la servidumbre.

- Lenguaje: volumetría simple de muros encalados, ornamentación concentrada y pocas aberturas hacia el exterior, pues la vida se verifica en el interior de la casa.

- Técnica: cubiertas maderiles con tejas musleras, bóvedas y arcos de medio punto.

Simultáneamente con estos elementos compartidos, cada región imprime a la tipología residencial características singulares que responden a modos de vida, condicionantes tecnológicos, climáticos, expresivos y simbólicos. Se producen así los ya referidos procesos de hibridación, como se ejemplifica a continuación.

En Perú, la capital virreinal, Lima, cuenta con ajimeces en esquina, logias miradores, solanas y los distintivos balcones maderiles exentos, como se observa en el palacio Torre Tagle (figura 1). El patio y la escalera configuran tanto la imagen interna como la portada externa. No era frecuente encontrar la escalera encajonada, sino que se localizaba directamente en el patio. La ornamentación se materializa con azulejería, pintura mural, telas y papel pintado.

En Cusco, ciudad andina, la piedra andesita fue el material utilizado por excelencia. El sistema de comunicación se realiza por galerías en las crujías de la fachada y corredores laterales que a la vez son balcones. También se observan balcones externos, no cerrados como los limeños, que apelan a ajimeces y miradores. La escalera está en una caja y el color engalana los espacios principales. Un ejemplo es la vivienda del Inca Garcilaso de la Vega (figura 2). La incorporación de locales en la planta baja modifica el uso del patio familiar, aunque persiste el de servicio. 
Arequipa, territorio sísmico rodeado de volcanes al sur del país, presenta casas de una planta, sin balcones ni galerías, y un sistema de cubierta totalmente particular: bóvedas paralelas a la calle, ocultas detrás de un parapeto, que reemplazan a la cubierta inclinada de tejas musleras. La calidez espacial la otorgan la vegetación y los fuertes tonos de pintura (ocres y rojizos), como lo manifiesta la vivienda del Moral. Las fachadas incorporan, sobre las aberturas, "portadas tapices", llamadas así porque el tallado de la piedra volcánica posibilita una ornamentación muy planimétrica, recrea motivos de la flora y fauna local y evidencia el parentesco entre las portadas civiles y religiosas en su estructura de composición.

En ciudades litorales del área guaranítica como Yapeyú (provincia de Corrientes, Argentina) y Santa Cruz de la Sierra (Bolivia), la vivienda cede su frente para formar una vereda cubierta a lo largo del amanzanamiento urbano. Las galerías se logran mediante columnas de madera y cubierta inclinada de tejas con escurrimiento directo hacia la calle, apta para climas húmedos y de fuerte asoleamiento.

La arquitectura residencial de Córdoba (Argentina), exhibe tecnología de tierra a través de tapiales elaborados con encofrados de madera, rellenos con barro y cañizo. Se emplea material orgánico como ligante y adobón, que son grandes piezas de tierra secadas al sol y cortadas. Es característica la utilización de la fábrica mixta en mampostería que fusiona ladrillos y piedra bola. La única vivienda de este período aún en pie en la ciudad es la del Marqués de Sobremonte.

Las viviendas salteñas, al norte de Argentina, se distinguen por su ingreso directo al primer patio, sin jerarquización del zaguán. Los patios cuentan con escaleras, filtros de agua y balcones-corredores maderiles, como se aprecia en la casa Uriburu. Tanto Salta como Córdoba presentan ejemplos de otra escala, por la menor subdivisión del lote y el desarrollo más orgánico asociado con el ámbito rural. 
La residencia aristocrática mexicana, similar a la de carácter cortesano, incorpora el entresuelo clásico de Cádiz y se configura en torno a patios. Ejemplo es la Casa de Alfeñique o de Francisco Morales, en Puebla (figura 3). Por su parte, en Antigua, al sur de Guatemala, se aprecia la tendencia a la horizontalidad antisísmica, planta con tejaroz, puerta central, balcones en ángulo, patios bajos y amplios.

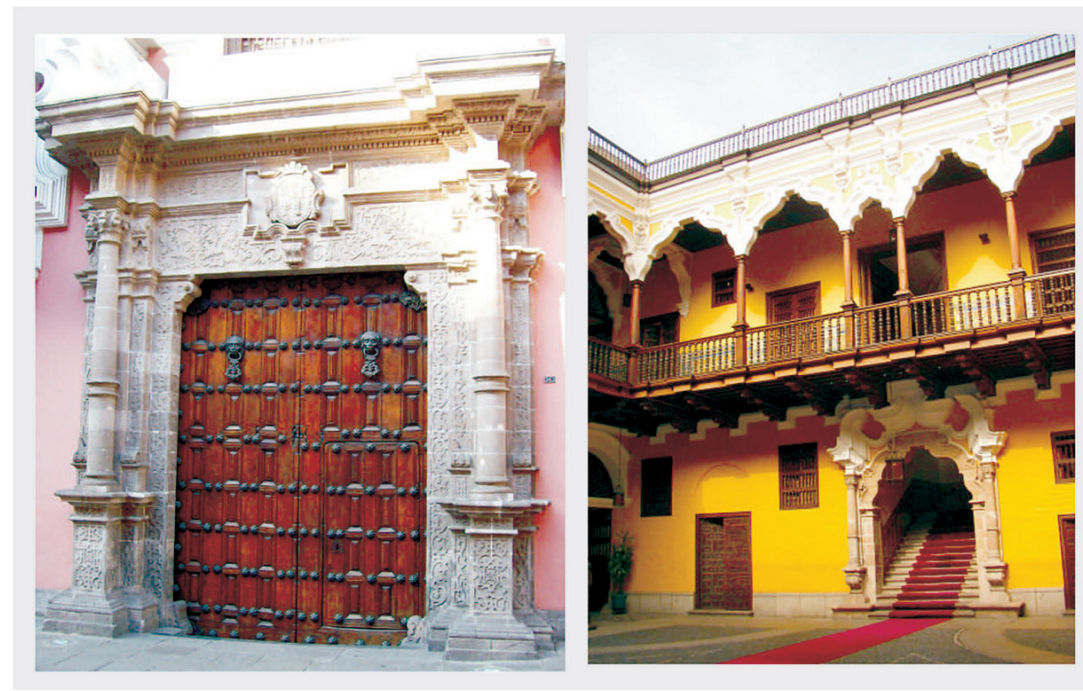

Figura 1. Palacio Torre Tagle, Lima, Perú. Fuente: autores. 

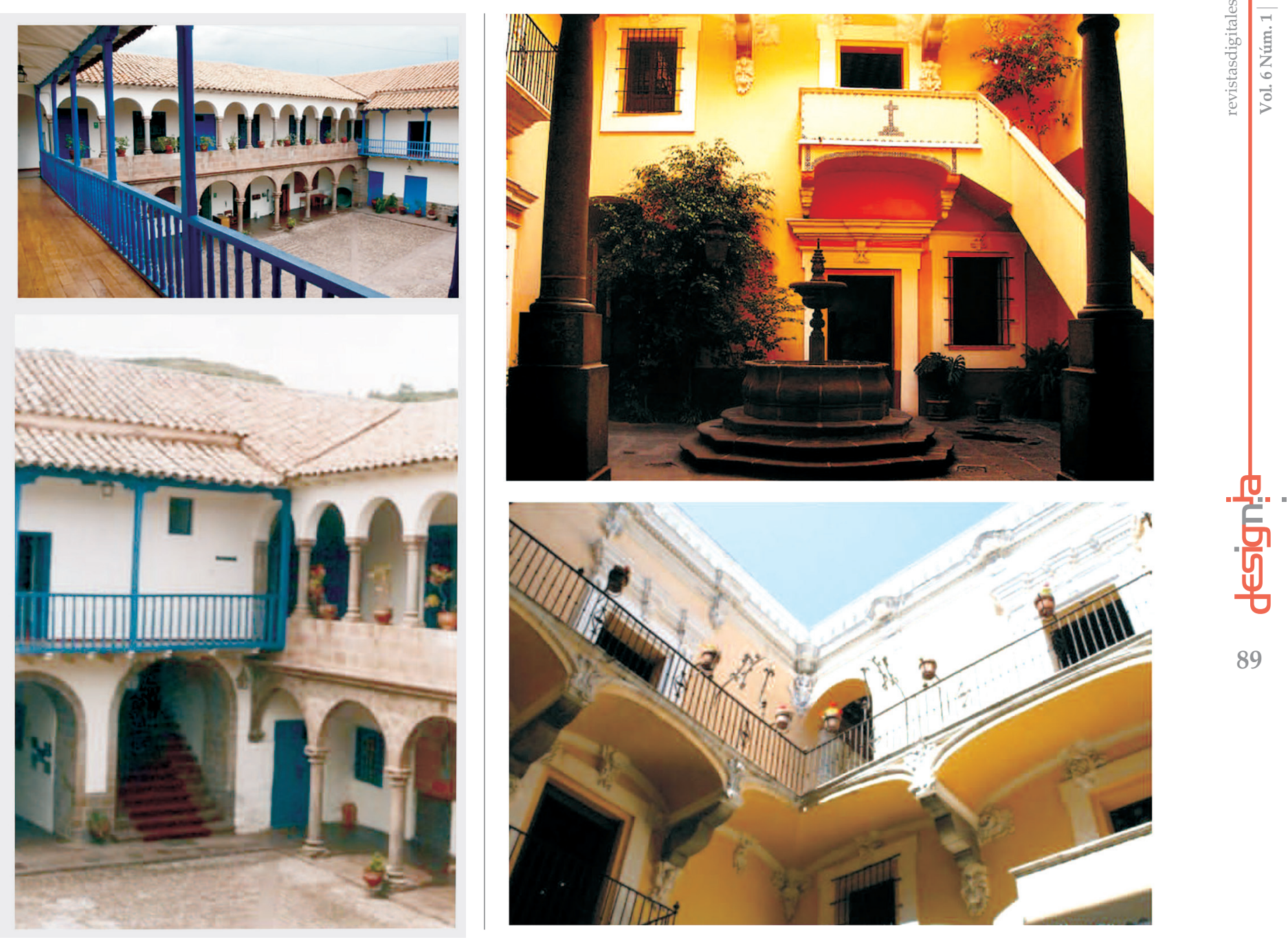

89

Figura 2. Casa del Inca Garcilaso de la Vega, Cusco, Perú.

Figura 3. Casa de Alfeñique, México.

Fuente: autores. 
La Habana (Cuba) sobresale por el uso profuso de entresuelos, donde también se albergaba a esclavos. Los patios se rodeaban de galerías o balcones y solían servir de pasillo, dada la pequeñez de los lotes. La presencia o ausencia de escalera en este lugar era relevante en la distribución espacial. En el siglo XVI prevaleció la tecnología de tapia, en tanto los muros de piedra lo hicieron en el XVIII.

Las viviendas quiteñas del siglo XVII en Ecuador se estructuran en torno a patios con pequeñas galerías perimetrales. La escala de la obra en relación con la ciudad, la conexión entre llenos y vacíos, el código semántico, la secuencia espacial, la organización funcional y el vínculo entre las resoluciones y los recursos disponibles en la región, son aportes que pueden transferirse al diseño arquitectónico.

\section{Vivienda en el siglo XIX en Argentina}

En Argentina, el período entre 1870 y 1930 representa la consolidación de la república y el afianzamiento, apogeo y declinación del liberalismo económico y político, lo cual da un nuevo rostro al país en su formación como nación. La llegada del ferrocarril en 1870 y el subsecuente aluvión inmigratorio produce profundas transformaciones que se reflejan en la morfología urbana. El cambio en la composición étnica y demográfica, las variaciones de las estructuras económicas, el proceso acelerado de urbanización, la verticalidad del poder e, incluso, la difusión de nuevas pautas de prestigio y gusto, modifican las costumbres, los valores culturales y los patrones de la estratificación criolla. El punto de partida es la negación de lo prexistente, cuya semántica es sinónimo de atraso, y se apela a principios y modelos decimonónicos, postulados por las academias de Bellas Artes. A finales del siglo XIX se observan las tipologías gubernamentales, sanitarias, educativas, culturales y religiosas que el crecimiento de las ciudades demandaba.

Para Miguel Barreto (2001), el espacio urbano del siglo XIX se ordenó en función de las actividades emergentes referidas al ocio recreativo y al consumo. El espacio público tomó el protagonismo de la ciudad como estructurante entre los nuevos tipos arquitectónicos, las nuevas infraestructuras y la diversidad social que surgía. La tipología residencial no fue ajena a esta situación y manifestó los cambios en los modos de vida. Palacios urbanos, petit hotels, villas suburbanas, casa de renta, viviendas de patio y de medio patio $y$, posteriormente, conventillos, comenzaron a sustituir las edificaciones coloniales y a extender la traza fundacional.

El crecimiento demográfico y la rentabilidad del suelo generaron otras subdivisiones del lote urbano y nuevos tipos arquitectónicos. La vivienda de patios y la de "medio patio" adaptaron la tipología colonial introvertida a las nuevas formas de vida "europeizantes" y se ejecutaron en terrenos con frentes de distintas dimensiones. 
La denominación "de medio patio" alude a la partición longitudinal de la vivienda colonial y se caracteriza por desarrollarse en lotes muy angostos y profundos. Se presenta como una sucesión de zonas cubiertas alrededor de patios para conformar un esquema tipológico cuyo uso es independiente de la orientación. También recibe el nombre popular de "casa chorizo" por ser estrecha y larga.

Es un tipo urbano y unifamiliar -aunque también sirvió como inquilinato- de una sola planta y azotea, con frecuencia situado entre medianeras y construido sobre la línea municipal, organizado tipológicamente a partir de la sucesión de patios y espacios cubiertos. El acceso se produce por un zaguán, por lo general lateral, que da al primer patio, el cual se encuentra recostado sobre una de las medianeras y sirve de recibo y nexo entre el exterior y el interior. Ante esta zona de uso social se abren las habitaciones principales, como son la sala, con grandes ventanales hacia la calle, y los dormitorios, ubicados sobre la otra medianera y vinculados entre sí por puertas interiores que generan servidumbre de paso y ausencia de privacidad. El comedor se dispone, muchas veces, de manera transversal, a modo de esclusa entre el primer y el segundo patio, ámbito de las actividades familiares. Cocina, sanitarios, depósito y cuartos de servicio ocupan un tercer patio, usualmente integrado a la quinta, el jardín y el gallinero. La relación entre las áreas abiertas se realiza a través de galerías cuya presencia posibilita transiciones transparentes. El sistema lingüístico contenido en la fachada no se deriva de una actitud teórica y reflexiva, sino de imágenes formales adaptadas por la interpretación personal de albañiles y alarifes italianos anónimos, quienes traen consigo la experiencia práctica de la construcción y el modelo arquetípico de la arquitectura clásica en su memoria. La organización académica de este componente manifiesta la constante estructuración de la modulación del plano, la clara diferenciación entre basamento, cuerpo y coronamiento, ritmos verticales y horizontales, simetrías y ricas y diversas ornamentaciones. Las grandes aberturas son jerarquizadas por su tamaño, enmarque y herrería, y algunas poseen balcones con una función de "palco" desde donde se observa el espectáculo de la vida "cosmopolita" de la ciudad. El lenguaje austero, representativo de los principios republicanos propios de la joven nación, opera como telón urbano para facilitar el acto de "parecer", prevaleciente ante todo. Los nuevos materiales, entre ellos el hierro y el vidrio, producen transformaciones espaciales: el primer patio, cubierto con claraboyas y mamparas de vidrio coloreado y decorado, se convierte en un lugar significativo, sin perder su carácter luminoso. 
Uno de los ejemplos más destacados de esta tipología en Córdoba es la casa Garzón Maceda (figura 4), situada en el centro de la ciudad. El aporte al diseño lo brinda la singularidad otorgada a la obra, en medio de la gran masa construida. A pesar de tomar cánones compositivos clásicos, quienes trabajaron en ella, italianos en su mayoría, lo hicieron con total libertad. Así, reelaboraron modelos según su memoria y las formas aprendidas, para lograr un producto propio y único que si bien forma parte de un conjunto, tiene entidad en sí mismo.

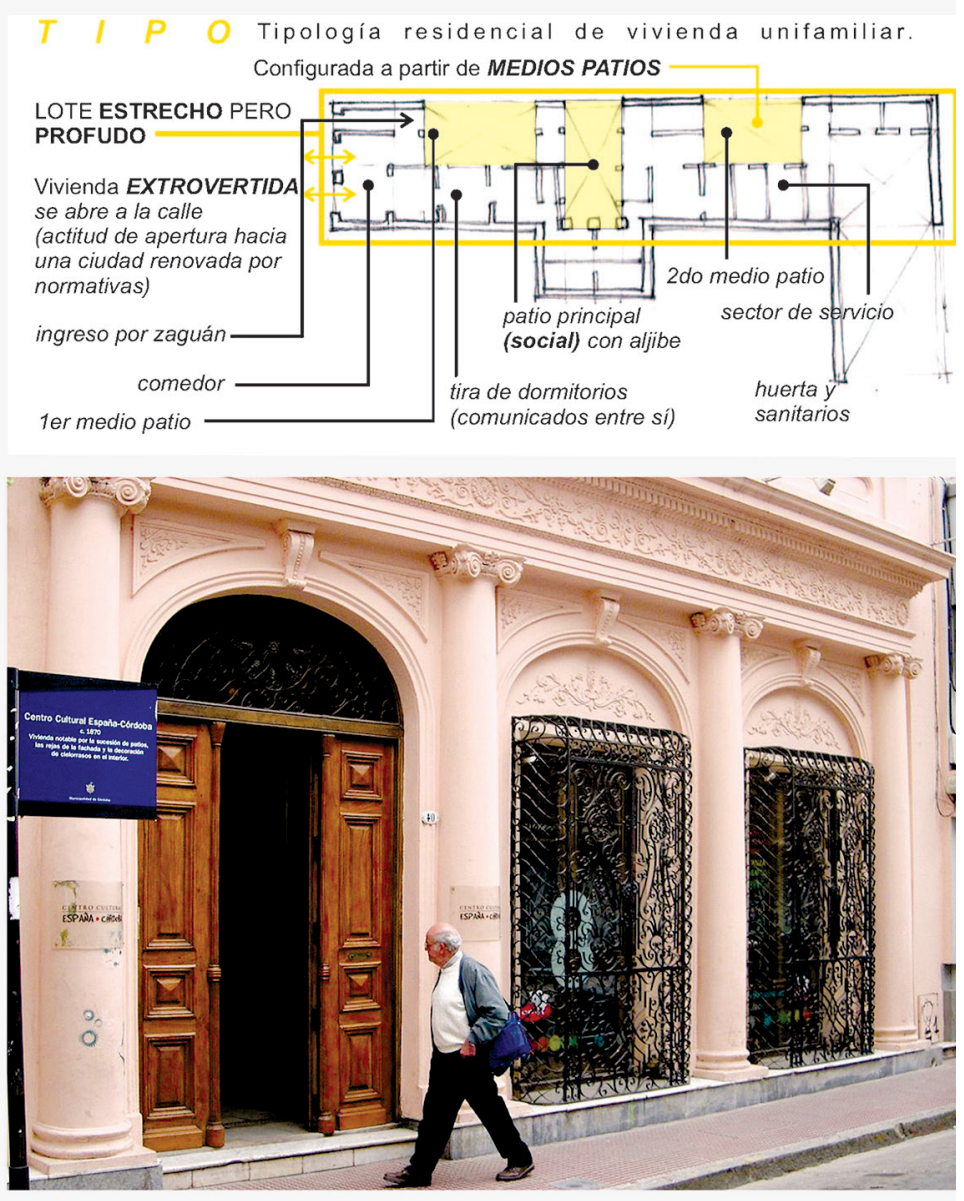

Figura 4. Garzón Maceda, Córdoba, Argentina. 
A lo largo del siglo XX, dos corrientes unificadoras recorren Latinoamérica: el racionalismo de vanguardia y un movimiento vinculado a la tradición, como afirmación a la búsqueda de la propia identidad (Días Comas y Adriá, 2003). El Movimiento Moderno fue más allá de las particularidades nacionales y unificó, en un lenguaje común, las arquitecturas de los años treinta, cuarenta y cincuenta. Sin embrago, las primeras respuestas a problemáticas regionales no consiguieron sobresalir en el escenario moderno. Solo hasta después de la Segunda Guerra Mundial la naturaleza "conservadora" de la ciudad-jardín fue aceptada y, en consecuencia, la vivienda resurgió como tema junto a las condiciones propicias para su desarrollo. Si bien no se detectan numerosos ejemplos de casas de patios como referentes del discurso racionalista en las primeras décadas del siglo en Hispanoamérica, uno muy significativo es la Casa Curuchet en La Plata (Argentina), diseñada por el maestro Le Corbusier y dirigida por el arquitecto argentino Amancio Williams. Organizada a partir de un espacio central donde se destaca la presencia de un árbol que actúa como límite virtual entre la zona pública y la privada, posee dos volúmenes diferenciados gracias a los cuales cada función se distribuye en forma clara y los espacios se organizan bajo características particulares.

A mediados de siglo y dentro de la búsqueda alternativa a los dictámenes del racionalismo abstracto -con su discurso monolítico y único- comienzan a revelarse posturas que revalorizan lo local, lo vernáculo y propio, sin dejar de lado la herencia moderna. La denominación "Casas Blancas" califica una manera de concebir la arquitectura doméstica -la casa- que mixtura recursos tecnológicos, espaciales y simbólicos tradicionales con requerimientos vigentes. En esta búsqueda de las raíces del ser real y el verdadero espíritu, el patio es protagónico y central en el diseño de la vivienda. Es fuente de luz y cualidad espacial por excelencia.

Destacan ejemplos como la casa Ellis, de Eduardo Ellis (figura 5), en Pacheco, Buenos Aires; o la casa Díaz, de José Ignacio “Togo" Díaz, en Córdoba, muestra representativa de su producción residencial neta y trascendente. Dentro de esa actitud que establece una dialéctica equilibrada entre el "espíritu de la época" y el "espíritu del lugar" (Browne, 1988), también sobresalen casos concretos de viviendas donde el patio como centro es retomado y resignificado. De estos hacen parte: casa Gilardi, de Luis Barragán, en Ciudad de México (figura 6); casa Ghezzi, de Juvenal Baracco, en Perú (figura 7); la resolución de una vivienda en Río Frío, Colombia (figura 8), por Rogelio Salmona; y creaciones más recientes como la Casa Esmeraldina, proyectada por Solano Benitez en Paraguay (figura 9). 
Ante una postmodernidad que tiende a diluir fronteras y homogeneiza la producción arquitectónica global, estos ejemplos aportan reflexión crítica a los modelos transculturados y vuelven la mirada a lo esencial: la materia, el color, las texturas, la luz, el medio geográfico y sociocultural. Demuestran que la economía de recursos no es un impedimento para producir obras de excelente factura y cualidad espacial.
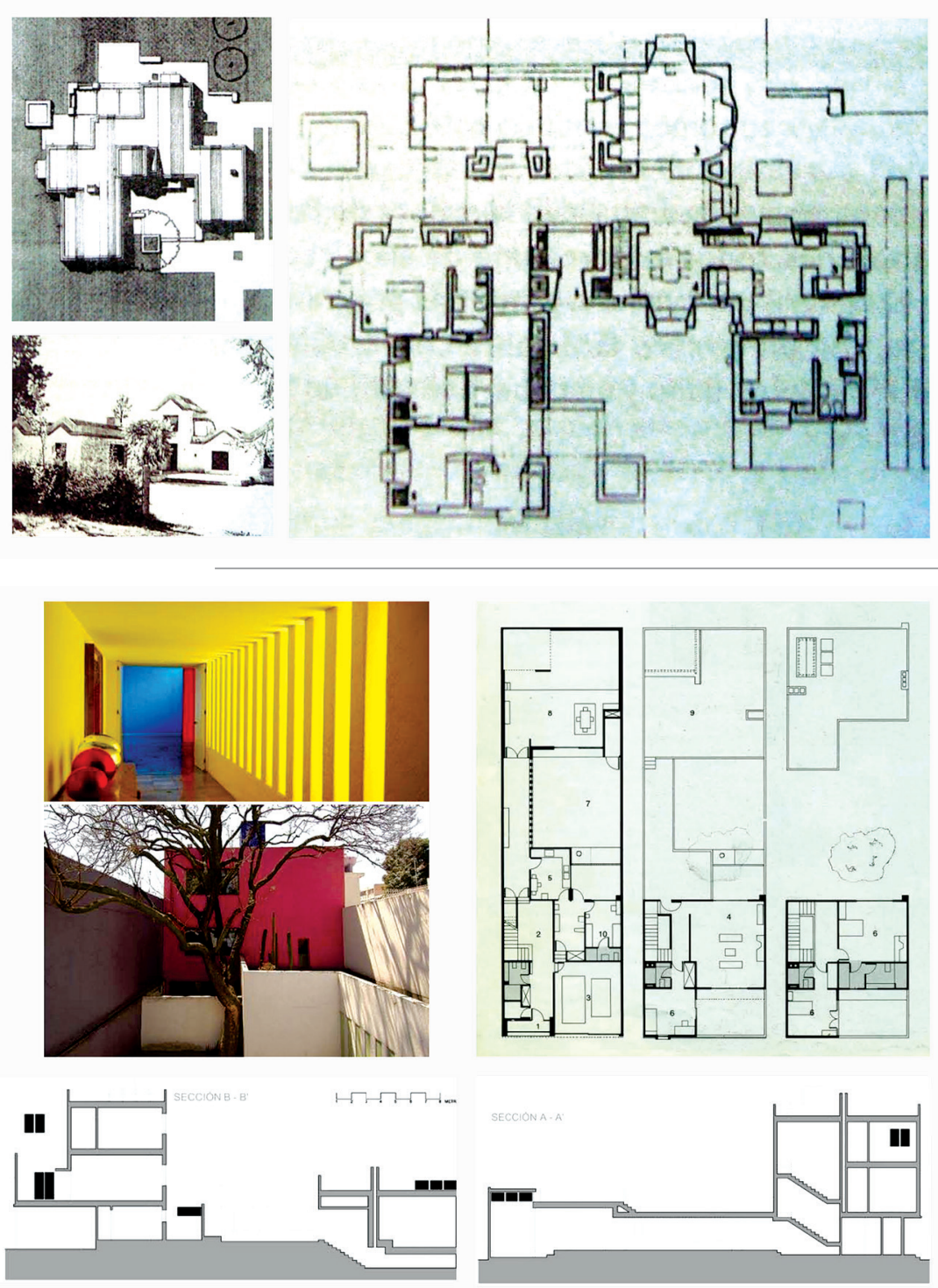

Figura 5. Casa Ellis, Argentina. Figura 6. Casa Gilardi, México Fuente: autores. 

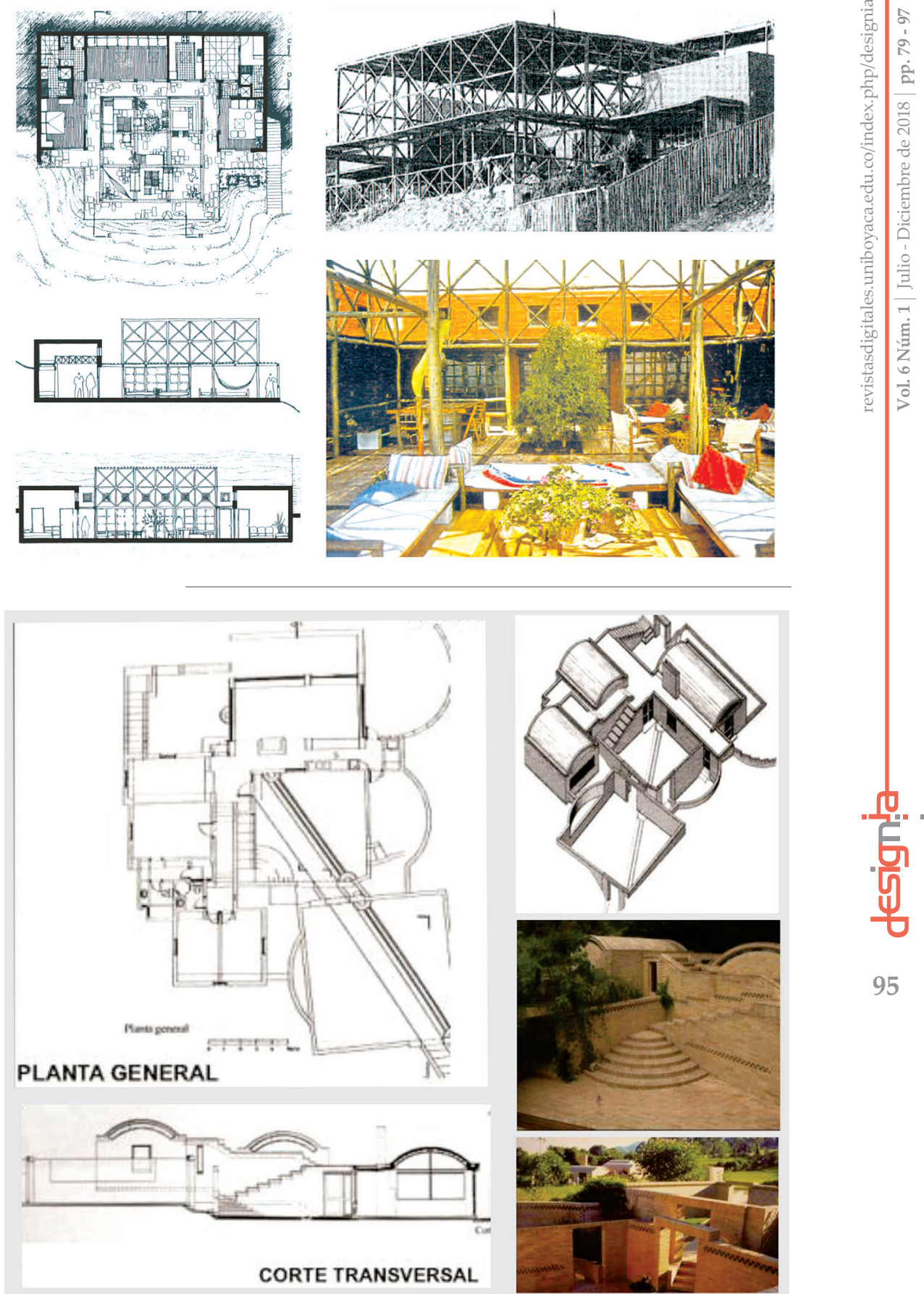

Figura 7. Casa Ghezzi, Perú. Figura 8. Casa en Río Frío, Colombia. Fuente: autores. 

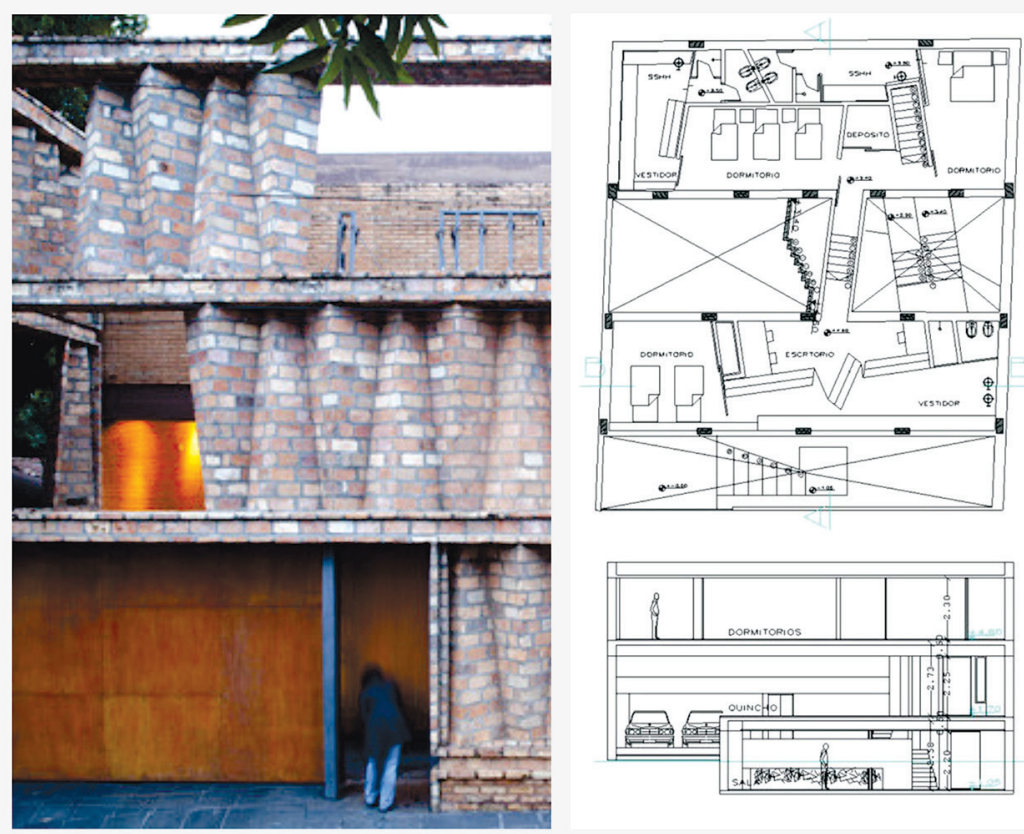

Figura 9. Casa Esmeraldina, Paraguay. Fuente: autores.

\section{CONCLUSIÓN. VIVIENDA, DISEÑO, IDENTIDAD}

Los procesos de hibridación, como los denomina García Canclini (2001), tallan nuestra multiforme idiosincrasia y son característicos de las formas de pensar y hacer latinoamericanas. La tensión entre lo autóctono y lo exógeno, lo auténtico y lo imitado, la barbarie y la civilización; entre tendencias centrípetas y centrífugas, define nuestra identidad dinámica, en constante crecimiento y decrecimiento.

A partir del trabajo realizado en el marco de la problemática del ejercicio de la docencia en al área de Historia de la Arquitectura latinoamericana y de su articulación con el diseño, puede afirmarse que la vivienda hispanoamericana de patios colabora profundamente en construir, delinear y manifestar la identidad particular de cada región y el carácter mestizo de nuestra cultura. El patio aporta patrones transferibles al diseño arquitectónico, "hermana" las situaciones regionales y recuerda que nuestra esencia es la misma. El poeta sevillano Joaquín Romero Murube expresó: “Esto es esencial: el cielo. Un pedazo de cielo para nosotros solos. El cielo dentro de la casa (...) El patio aísla del mundo en torno, y sólo admite una vecindad franca: la celeste" (citado por Silva, 2001, p. 875-876). 


\section{REFERENCIAS BIBLIOGRÁFICAS}

Alcalá, L. (Comp.). (1995). Pensar la vivienda. Madrid: Ágora-Talasa.

Barreto, M. (2001). El espacio urbano y la vida urbana de la ciudad moderna. Recuperado de http://www. unne.edu.ar/unnevieja/Web/cyt/cyt/2001/1-Sociales/S-030.pdf

Bauman, Z. (2002). La modernidad líquida. Buenos Aires: Fondo de Cultura Económica.

Browne, E. (1988). Otra arquitectura en América Latina. México: Gustavo Gili.

Días Comas, C. \& Adriá, M. (2003). La casa latinoamericana moderna. México: Gustavo Gili.

García Canclini, N. (2001). Culturas híbridas. Estrategias para entrar y salir de la modernidad. Buenos Aires: Paidós

Iglesia, R. (2006). El espacio doméstico. Buenos Aires: I+P.

Larraín, J. (1994). Ensayo de la identidad latinoamericana. Teoría e Historia. En: Estudios Públicos, CEP, No 55, Santiago de Chile.

Montaner, J. (2011). Arquitectura y crítica en Latinoamérica. Buenos Aires: Nobuko.

Rojas Mix, M. (2004). Los cien nombres de América. Eso que descubrió Colón. Córdoba, Argentina: Universidad Nacional de Córdoba.

Romero, L. (1997). Latinoamérica: las ciudades y las ideas. Buenos Aires: Siglo Veintiuno.

Silva, M. B. (2001). La vivienda a patios de origen hispánico y su difusión en Iberoamérica. En A. Moreno (Coord.). Actas del III Congreso Internacional del Barroco Americano: Territorio, Arte, Espacio y Sociedad (pp. 875-896). Sevilla: Universidad Pablo de Olavide.

Taberna, J. (2008). La Casa. Cuaderno Latinoamericano de Arquitectura 30-60, (17), Córdoba. I+p editorial. (pp. 28-33).

Yujnovsky, O. (1984). Claves políticas del problema habitacional argentino 1955-1981. Buenos Aires: Consejo Latinoamericano de Ciencias Sociales. 